\title{
Chapter 6: The IPCC experience and lessons for the IPBES
}

\author{
Daniel Compagnon, Wolfgang Cramer
}

Large-scale environmental assessments involve the participation of many scientific disciplines, even more so when repeated throughout the decades and be implemented in institutionalized context such as the IPCC and the IPBES. Although the purported function of these international organizations is to provide a working interface between science and the decisionmaking circles at international level, the "boundary work" concerns as much the coordination between scientific disciplines not used to work together and lacking a common language, as it defines the interactions between the world of politics and that of scientists. The development of common standards for scientific evidence and plausibility is crucial, both within and then between the natural and social sciences. The challenge is to produce statements of greater clarity than otherwise found in scientific publications for the use of policymakers, without compromising the established scientific standards.

The institutional similarities between these two international organizations are deliberate and originate from the same willingness of the UN member states to retain some control over potentially far-reaching scientific assessments (see chap. 2 above). Institutional differences are largely a consequence of more than two decades of experience between the establishment of the IPCC and that of IPBES, and the creation of a more favourable political "climate" during this time: Today, many member states recognise more clearly the potential for valuable policy support provided by science-policy interfaces as compared to the 1980s. Likewise, lobbying groups from all kinds of political background sense the need to actively relate to the existing science-policy interface. The development of IPBES will hopefully benefit from the IPCC experience in both areas, interaction with policymakers and complex scientific coordination. Therefore, it is important to understand the nature of the IPCC and its limits and shortcomings, and also to understand the differences between the two institutions.

The first section of this chapter reviews the social sciences literature devoted to the IPCC and its reports without endorsing all the opinions expressed, to reflect on the kinds of problems and challenges the IPBES will have to face. The second section, based on the personal experience of the second co-author, both in the IPCC and in the nascent IPBES, illustrates these problems and emphasises the specificities of the IPBES in its early stages.

\section{The ambiguities of the IPCC "model"}


Originally seen as a specialized and obscure institution, the International Panel on Climate Change (IPCC) has become the iconic example of a strong influence of science in the construction of international environmental regimes, even though this picture is not totally accurate. Its status in the public opinion was greatly enhanced by the 2007 Nobel Peace Prize (shared with Al Gore). There is a large literature on the IPCC, only part of which is in political science/international relations (for a review, Hulme \& Mahony, 2010).

The IPCC was established in November 1988, on the request of the G8 countries, under the authority of the World Meteorological Organization (WMO) and the United Nations Environmental Program (UNEP), a move condoned by UN member states in a General Assembly Resolution 43/53 of 6 December 1988. The Toronto conference organized by UNEP in June 1988, when discussions about IPCC were under way, underlined both the importance of the issue and the lack of scientific consensus (in particular within the US scientific establishment) on both the reality and the causes of climate change. It was the outcome of a decade of attempts to tackle the scientific challenges of climate change, in particular the World Climate Programme (WCP) a research initiative under WMO, UNEP and International Council of Scientific Unions (ICSU), set up in 1979.

The intergovernmental nature of the new organization underlined that many governments wanted to exert some effective control over the production/dissemination of credible, legitimate policy-relevant knowledge on climate change. The US and British conservative governments in particular did not trust UNEP, which they perceived as partial to the NGOs and the developing countries, and whose Executive Director Mostafa Tolba had been a strong advocate of a climate convention since 1985 (Agrawala, 1998). As the different US government agencies were divided on the issue (in particular the Department of Energy vs. the Environmental Protection Agency), and huge business interests (fossil fuel related industries) were at stake, some US decision makers saw it expedient to claim that acquiring more knowledge was a prerequisite for action. To them, acting on the basis of the precautionary principle (such as in the Ozone Layer regime for example) was not an option. Establishing an international assessment mechanism under the United Nations control could serve to postpone policy action until the scientific basis was deemed robust enough. Others who supported the creation of IPCC hoped, on the contrary, that an independent, scientifically grounded organization would counterbalance the influence of business lobbies in policy-making and stimulate international policy cooperation.

In this context, the definition of the "science" on climate change was also a political question from the onset, although the organization's motto made it clear that its work was "policy-relevant and yet policy-neutral, never policy-prescriptive". It is quite ironic that in the late 1990s and early 2000s the IPCC stood accused by critics from the neo-conservative and climate denialist camp of having "politicized" the science of climate change. It is the intergovernmental nature of the IPCC that 
makes its assessments acceptable as a basis for policy-making by government negotiators in the UNFCCC. "However, having an intergovernmental status has imposed significant costs also: IPCC assessment summaries are widely regarded as being politically negotiated, which has, at times, undermined their credibility" (Agrawala, 1998: 611). Instead of just "speaking truth to power", the traditional function devoted to science (Price, 1965), climate scientists are involved in an political role through a process that produces, for the sake of policy relevance, what some people call “imperfect science" (Malnes, 2006).

The IPCC is indeed an intergovernmental cooperation organization, with nearly universal membership from 195 countries, and the Panel plenary is the core decision-making body attended by governments' representatives. Since the Panel plenary elects the IPCC chairperson and the members of the Bureau (including the co-chairs of the three working groups and the task force on GHG inventories) from candidates proposed by member states, the whole structure of the IPCC is kept under the close supervision of states. ${ }^{1}$ The fact that all these officials have a robust scientific track record does not diminish the influence of the states. In addition, the plenary also adopts the structure and mandate of IPCC Working Groups and Task Forces, the work plan of the IPCC, the scope and outline of IPCC reports, and it approves, at the end of the assessment process, the Working Group reports and the Synthesis reports rather formally, and the respective Summaries for policymakers on a line-by-line basis, until a consensus is reached. Therefore, the intervention of the member states is by no means limited to the final phase (see diagram below). IPCC works on a double consensus: scientific and political.

\footnotetext{
${ }^{1}$ The original division in three working groups was proposed by UNEP executive director Mostafa Tolba, a compromise owing more to politics than to science (Bolin, 2007: 49-50).
} 


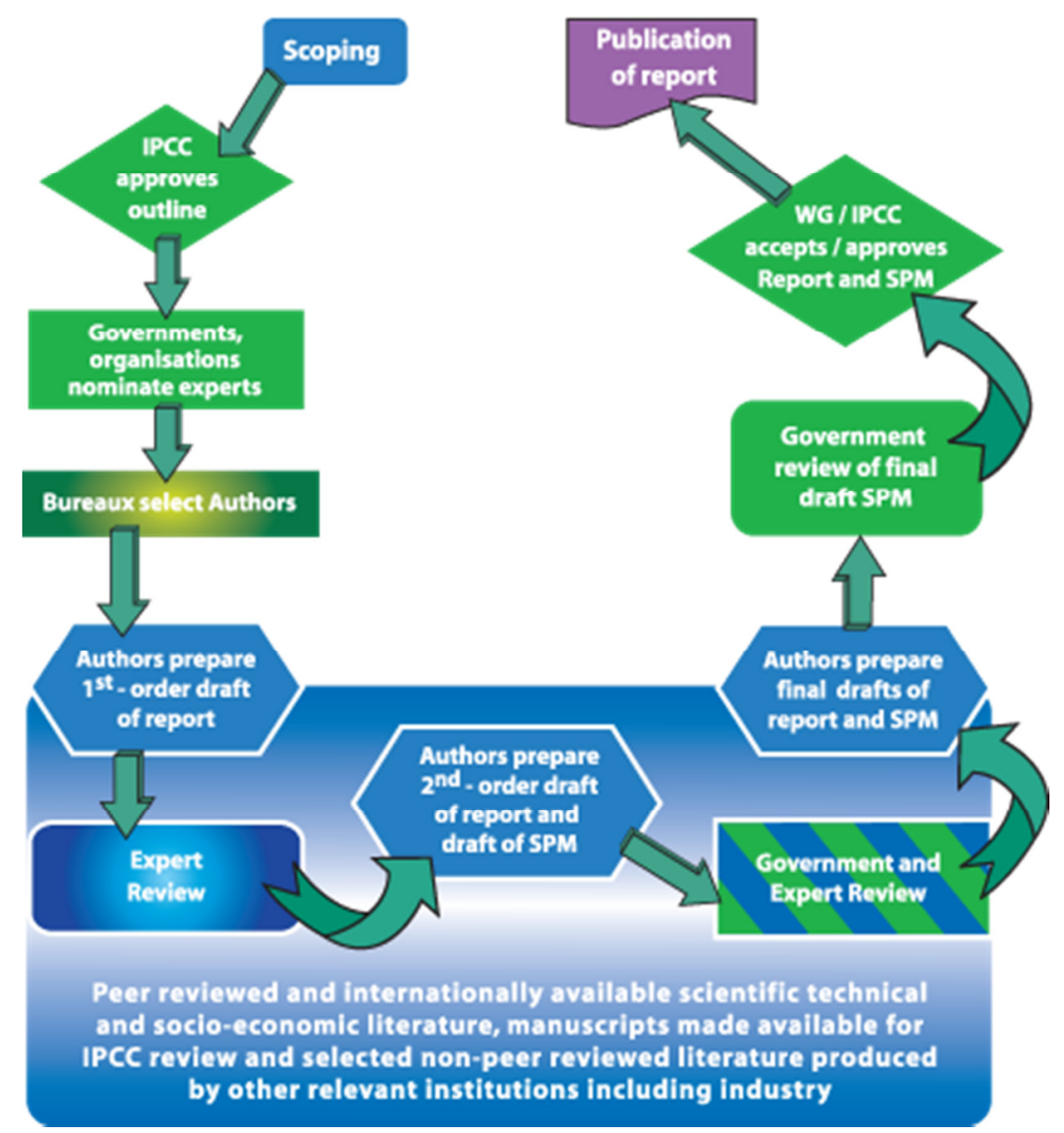

Figure 1 IPCC process from scoping to publication of report (Scoping is the preparatory meeting that proposes a scope and outline for the future report; see http://www.ipcc.ch/index.htm)

The USA, which had played an important role in WCP, had accumulated in the 1970s and 1980 s the largest body of knowledge on climate change through its national research programs, and was also then the leading emitter of greenhouse gases (GHGs) per country and per capita. The US government kept a close eye on the proceedings of the IPCC. In 2002, for example, the US government pressed for the replacement of British scientist Robert Watson, chairperson of the IPCC since 1996 and a former Associate Director for Environment in the Office of the US President, perceived as a "bête noire" of the US oil industry by the Bush administration as too outspoken on the anthropogenic causes of climate change (MacKenzie, 2002). The US government also objected to what it considered politically charged language in the Third Assessment Report (2001) (Haas, 2005:394). Governments from Russia and Saudi Arabia criticized the IPCC reports when seen as undermining their interests, but were opposed by other (notably European) governments who insisted on clear language and scientific credibility of these reports. These dynamics contributed to the politicisation of the process.

Some analysts see the control of states over the IPCC organization and the contents of the assessment reports diminishing over the years (Siebenhüner, 2003). Due to the implication of a 
growing community of scientists in the assessments and the writing of the three working group reports, the successive reports have gained in credibility. The IPCC produces no new research but collects material published in scientific and publicly accessible, mostly peer reviewed journals and books, and to a lesser extent from other sources, evaluated according to their relevance and scientific credibility. It also improved its internal procedures to control errors, following the controversy that developed over some errors contained in the Fourth Assessment Report (2007). The Inter-Academy Council was tasked to audit the IPCC procedures and make some recommendations in a context politically loaded by the release of climate scientists' e-mails (the "climategate" affair) just before Copenhagen in 2009. Following its report in August 2010 (IAC, 2010), a number of significant improvements to the IPCC procedures were introduced, although the main structures were maintained as they were. The reform stopped short of addressing "IPCC's relationship to public policy and to its various global 'publics' [and] its normative commitments in terms of accountability, political representation, and legitimacy“ (Beck \& al, 2014:82).

Indeed, the legitimacy of the IPCC is still contested by critics who emphasize the overrepresentation of scientists from the affluent West. Being a G8 recommendation the establishment of the IPCC was originally seen with suspicion by the developing countries, which were concerned that an organization dominated by Western scientists would foster the political and economic interests of the industrialized countries. Despite the Chair's and Secretariat's efforts to increase involvement of experts from the Global South and the election of an Indian chairperson Rajendra Kumar Pachauri in 2002, and 2008 again, the proportion of OECD/non OECD authors and reviewers remained stable through the years (Haas, 2005: 395; Hulme \& Mahony, 2010). Another perceived weakness of the IPCC process is the perceived bias against social sciences, regarded as lacking the rigor of the hard sciences, with the exception of economics where quantitative assessments are used in a way that can be understood also by the climate scientists (Bjurström \& Polk, 2011). Some observers see the same trend developing in the nascent IPBES (Morin et al. forthcoming). Many of the climate scientists having contributed to the IPCC reports are aware of these shortcomings, but the production of interdisciplinary knowledge stumbles on acute epistemological and methodological problems.

Social sciences still debate over the characterization of the IPCC: a scientific lobby, a political organization or both, an epistemic community or a "boundary" organization. The notion of "epistemic community" as defined by Peter Haas emphasizes the role of consensual, policy-relevant in regime making, however, defined as "a transnational network of professionals with recognized expertise and competence in a particular domain and an authoritative claim to policy-relevant knowledge within that domain or policy area" (Haas, 1992) does not fit with the structure of the IPCC. In Haas' case study-the Mediterranean Action Plan-the experts were embedded in the 
decision-making process and coordinated transnationally by UNEP, whereas the IPCC is a formal international organization and professes "policy-neutral" and certainly "not policy prescriptive" activities.

Although the First Assessment Report (1990) is said to have played a major role in the signature of the UN Framework Convention for Climate Change (UNFCCC), and the Second Assessment Report (1995) provided major inputs in the negotiation of the Kyoto Protocol, the publication of the reports did not coincide closely with the negotiation process, leading some observers to question their impact on policy-making (Haas, 2005: 396; Victor, 2015). The IPCC's major contribution has been to establish beyond doubt the reality of climate change, its predominant anthropogenic causes and the seriousness of its expected impacts, producing a "shared scientific understanding of the climate issue" (Lidskog \& Sundqvist, 2015:12). However, it failed to shape policy in any significant way, with the exception of EU policies or in countries like Norway, in the absence of "usable knowledge" at a scale (national and sub-national) where policy-makers need to take decisions.

The goal to limit global warming at $2^{\circ} \mathrm{C}$ above pre-industrial levels is often presented as an outcome of its reports is not in fact a IPCC recommendation at all but a political target. It appears for the first time in a decision of the European Council in 1996, resurfaces in a report of the German scientific advisory institute WBGU in 2007 as the limit of acceptable warming, it is then adopted by the EU as an comprehensible policy objective for the public, and is pushed in the negotiations until it is endorsed by the "Copenhagen Agreement" and the Conference of the Parties (COP) 16 held in Cancun November 2010 (Aykut \& Dahan, 2011). Its centrality as a policy objective and legitimate discourse on climate change is not backed by overwhelmingly scientific evidence. Science has always, throughout all IPCC reports, recognized that significant damages occur already now (at $1^{\circ} \mathrm{C}$, roughly), and that they will grow incrementally.

This example underlines how difficult it might be to endorse the interpretation of the IPCC as a "boundary organization" between the world of science and the world of politics as understood in the Science and Technologies Studies (STS). Far from being pure and neutral, science is embedded in social institutions and discourses. Scientific "truths" are relative to a social-historical context and knowledge is always contested. Because scientists respond to social demands, in particular from the policy-makers who largely set the research agenda, policy-relevant science is always a co-production (Jasanoff, 1996), or what Bruno Latour calls "hybridization" to reflect the blurred boundaries between science and policy. "Coproduction happens when policy influences the production and stabilization of knowledge, while knowledge simultaneously supports and justifies policy" (Lidskog \& Sundqvist, 2015:6). Whatever research findings are offered, policy makers will tend to be selective 
about what use and do not use. In return, IPCC contributed actively to the construction of climate change science as policy-oriented knowledge, with certain epistemic and methodological limits.

However, if the boundary organization creates a network of relations between scientists and decisions-makers, the Subsidiary Body for Scientific and Technological Advice (SBSTA) of the UNFCCC qualifies better than the IPCC in this respect, as it is officially tasked with translating science findings into policy advice and allowing government officials to mix with scientists on a regime implementation agenda, it engages in "hybrid management" (Miller, 2001). It is in Convention committees such as the SBSTA that discussions over policy issues ${ }^{2}$ take place as noted by the first IPCC chairman who attended many of its meetings (Bolin, 2007) at a time when the IPCC was kept separated from the UNFCCC. That the SBSTA decided to "act as the interface between the IPCC and the climate regime, with the IPCC submitting its reports to SBSTA“ (Miller, 2001: 260) and to create a joint liaison group between the two institutions, underlines that the IPCC in itself is not the real science-policy interface as often suggested. Although, being a typical UN forum following the consensus rule of procedure, the SBSTA has moved at a slow pace and its proceedings were heavily politicized although allowing a greater participation from smaller countries and attention to their worldviews (Ibid: 268).

Besides, does the IPCC really sit "on the boundary"? The analysis of its structure and rules of procedure briefly sketched above rather suggests that it is fully inter-governmental, with the original intent "to keep science on a tight leash" (Haas 2005: 396). Yet, we should differentiate within the IPCC the large community of scientists who are contributors and lead authors to the various chapters of the working group reports, and the Panel of government representatives. In retrospect, it seems that through this duality-IPCC and SBSTA-the principals (governments) carefully circumscribed the role of science in the climate change regime in order to retain a large autonomy of political decision. They could not, however, prevent the IPCC reports from gaining a wider audience in the media and civil society, which in turn has exerted a certain pressure on decision-makers. Thus, it is through the public space (in the sense of Habermas and Dryzek) that IPCC reports have influenced policy-making in a broader sense.

From the history of the IPCC, there are significant lessons to be drawn for the IPBES. Largely inspired by the IPCC (Larigauderie \& Mooney, 2010), the platform on biodiversity and ecosystem services is also an intergovernmental organization where the Plenary is the main decision-making body. It is positioned in relation to the CBD very much in the way the IPCC is in relation with the UNFCCC, outside the negotiation process, and IPBES relies on member states for implementation

\footnotetext{
${ }^{2}$ The SBSTA concerns itself with other issues than climate risk assessment, such as technology transfers, standards and methodologies for measuring emissions and abatement efforts.
} 
(see chapter 3 above). The CBD also has a Subsidiary Body on Scientific, Technical and Technological Advice (SBSTTA) to provide policy-relevant advice to the parties. In addition, the status of IPBES assessments in relation to the Global Biodiversity Outlook (GBO) regularly published by the CBD Secretariat is yet to be decided. The same challenges of involving more scientists form the global South, or of balancing different knowledge systems are facing the IPBES too. Once again, at the beginning of IPBES, some observers pointed at the quasi-absence of social scientists in the governance of the organization, when social sciences could help develop a more self-critical and reflexive approach to knowledge (Lemos \& Morehouse, 2005). However, since 2015 and the more explicit integration of non-scientific systems of knowledge, including local knowledge from communities playing a key role in conservation of natural resources and habitats, four social scientists are involved in the MEP ${ }^{3}$.

The next section will explore the similarities between the IPCC and the IPBES from the personal experience of a scientist, Wolfgang Cramer, who was involved in both.

\section{IPCC and IPBES from within}

Participating in science-policy interface work is a challenge for most scientists and can be a life-changing experience for some. Arguably, no other field of science than climate (and now biodiversity science) offers the same opportunity for intensive exchange about key issues between decision makers in international politics and the scientific community. A guiding principle is mutual respect, captured prominently by the principle "policy-relevant but not policy-prescriptive", which initially poses problems for some scientists who believe that it is their role to convince the policy maker of the need to act. So the first lesson to learn is not only to speak clear and jargon-free language, but also to listen, and to understand the professional context within which the policy maker plays his/her role.

What is rarely recognised by outsiders of the process is that the participation of researchers in science-policy interface work is on a voluntary basis - both for the IPCC and IPBES. There is no remuneration and there is the expectation that a large amount of time needs to be invested. Indeed, most scientists consider it an honour to be invited to contribute, and they invest significant amounts of their spare time in this work. Most roles are assigned by invitation, involving a selection procedure that gives preference to scientific credentials, but then also strives to involve "political" elements such as the goal to increase the participation of colleagues from low-income countries, an adequate gender balance and also a rich participation from different scientific disciplines. While this process

\footnotetext{
${ }^{3}$ In 2015, 4 among the 25 MEP's members are social scientists (Marie Roué, (Anthropologist), Unai Pascual (Economist), Marie Stenseke (Human geography) and György Pataki (Management and communication)).
} 
makes a great point of departure for the building of an international expert community, it also creates an obstacle to wide participation because many scientists do not work in positions where they can, at their own discretion, allocate a part of their time (during or outside working hours) to the IPCC or IPBES.

I will look, from my personal perspective, at a few of the different roles participation in the IPCC can imply for an individual scientist - many of these roles exist in similar ways for IPBES. Clearly the most accessible role is that of a reviewer. For the Fifth Assessment Report, invitations to review chapter drafts were sent out very broadly, and any interested expert was given access to draft documents in order to provide comments on them. The role of these reviewers is hugely important for the quality of the assessment, but it provides little to no benefits to them in terms of enhanced reputation or career advantages. It is therefore often hard to motivate scientists to carefully review report drafts. Yet their contributions are more and more important, given that, due to the growing amount of published scientific knowledge, the full amount of information can hardly be assessed by an individual report author any more. Even if a reviewer reads only some section, for whatever reason related to personal interest, the contribution will be useful and appreciated by report authors. I first reviewed draft IPCC chapters for the Second Assessment Report, in 1991, spending many days with them. While reading, I learned a lot about scientific studies I was unaware of, but also found gaps and mistakes. My sometimes detailed responses led to an invitation to one of the author meetings, and I so became more deeply involved in the process. In particular, there was an intensive and unresolved debate within one of the author teams where my comments helped resolve the issue.

The process of writing chapters has changed substantially during the past 25 years, because the amount of scientific literature keeps increasing, and the ambition still is to provide a comprehensive overview of the available knowledge. Without active reviewers, this can no longer be achieved, and it will be important to increase the number of experts participating in the process.

Other roles for the IPCC or IPBES are usually assigned after some nomination and selection procedure. National "focal points" in most countries assist their governments in this process, usually with the aim of encouraging participation from their country in the platform. Being a "lead author" is a rather important role. These experts are asked to summarize the knowledge for some part of the science covered by a chapter, to provide text for inclusion, and to consider the comments that have been made by the reviewers. As lead author in various chapters of the Third and Fourth Assessments of the IPCC, I had the opportunity to work closer than otherwise with some leading scientists in my discipline, and several highly useful professional collaborations have arisen from these exchanges. Being a lead author also inevitably broadens your view of your own field of science, as you must also assess literature from topics outside your "scientific comfort zone". Authorship at this level, as 
member of a small international team, is a great opportunity to sharpen one's abilities to identify "key findings" and present them in a way that communicates them clearly to non-specialists. During the construction of the overall assessment, one can then watch, and engage with, the process of synthesising key findings into an overall message that is perhaps later found in the summaries of the chapter, the working group volume or even the overall assessment report.

A basic but permanent problem for authors is the limitation in the space they are given. Much of the time, authors find their topic extremely important and they struggle to provide text that contains precise information while still being short enough to be accessible to the reader who typically looks for information on a large number of topics at the same time. Another problem is that "assessment" implies not only to report facts that are documented in the literature, but also to provide statements of their reliability. In ecosystems, for example, species often come and go, due to natural fluctuations, due to direct human interference, or due to climate change. In an assessment of these changes, the author is expected to provide clear guidance on the relative role for these different "drivers". When there is no definitive answer (a situation arising frequently), then the author must communicate just how uncertain a given conclusion is, considering all available evidence. To help authors achieve this task, the IPCC produces fairly detailed guidance documents. In recent reports, authors have used what is referred to as "calibrated uncertainty language", a useful tool but one that requires training and therefore additional time investment for authors.

A particularly significant task for the IPCC is that of a "coordinating lead author" - I have had this role in the recent (fifth) assessment, co-leading a chapter on "detection and attribution of observed impacts" for its Working Group II (Cramer \& al., 2014). The coordinating task obviously implies the maintenance of a good communication process with the lead author's team which by necessity is a global team, involving colleagues from similar disciplines but different geographic and cultural backgrounds, in our case from Germany, USA, Sweden, Brazil, South Africa, and the Philippines. Given the great distances, such teams can meet physically only rarely, in our case only five times during the six years of work, at quasi-annual meetings, and it becomes therefore imperative that good electronic communications are put to use.

In our specific case, we identified a stronger-than-usual necessity to interact not only with each other but also with a large number of other chapters under preparation for the same report. This was because, in different regions and different scientific domains, the notion of what constitutes a scientifically plausible detection of some climate change impact from observations may differ. To ensure consistency, it was necessary to first develop clearer terminology and then train colleagues from different domains and regions in its use. Our objective was that all chapters treating regional issues or specific domains (like ecosystems, agriculture, settlement and others) would use the same methods for detection and attribution, thereby allowing our chapter to provide a synthesis on the 
basis of the others. To approach this goal, we created a "social network", connecting members of our own team electronically to contact persons in the 20 sectoral/regional chapters of the same report. With these individuals, we not only exchanged e-mails, but we also organized web conferences where we discussed our approach and its consequences for the assessment. During one author's meeting, in Buenos Aires (Argentina), we even rented a restaurant in order to strengthen our social links to the other authors, and this turned out to be successful.

What emerges from this experience of being a coordinating lead author is, firstly, that the task is much beyond the editorial effort of aggregating pieces of text into a coherent document. The early definition of the shared objectives, and the continuous monitoring of the process are crucial, internally for the chapter but also for the connection between the chapter and all others in the same working group report. The task therefore becomes a social process, demanding a substantial effort by the coordinator, as well as by everyone else involved. Increasingly, governments recognize that, due to the volume of available information, coordinating lead authors need support for carrying out this task. In our case, with support from the German government, the work was supported by an expert in climate change issues in her own right, who worked full-time for the chapter team without her, the result would have been a mere shadow of what the chapter is now.

IPCC reports strive to accessible syntheses by adding, to the chapters, executive summaries, and to the working group reports, a technical summary and a summary for policymakers. The preparation of the latter represents a particular challenge for the coordinating lead authors, as they must confront delegations of all governments in one week-long event called the "approval plenary". During this session, the full draft of the summary is projected on great screens, and every sentence of it is opened to questions by government delegates. For any statement relating to a particular chapter, the coordinating lead author must be ready to explain the underlying scientific evidence. While the situation itself may feel like an academic examination (something most of us had thought we would never again have to face in our professional life), this is also a satisfying opportunity to explain the findings, to seek understanding for them, and, if necessary, to modify them for further improve their clarity. It has sometimes been claimed that this is a situation of "negotiation", and it is true that one cannot help but feel that some governments raise issues with the sole purpose to weaken some statement. But the principles are clear and undisputable: the report is under the responsibility of the scientists only, and changes are made with the principal objective of reaching an unambiguous and scientifically sound text. There simply is no mechanism that could introduce, on government request, any statement that could be scientifically incorrect. Sometimes, text is deleted by the scientists chairing the discussion, because a significant number of government delegations considered that it could lead to misunderstandings on critical issues. 
As coordinating lead author for the chapter on detection and attribution of impacts of recent climate change that have occurred already, I faced an unexpected situation during the approval plenary for the IPCC's Fifth Assessment Report, in Yokohama in March 2014, while presenting a global map of observed impacts of climate change.

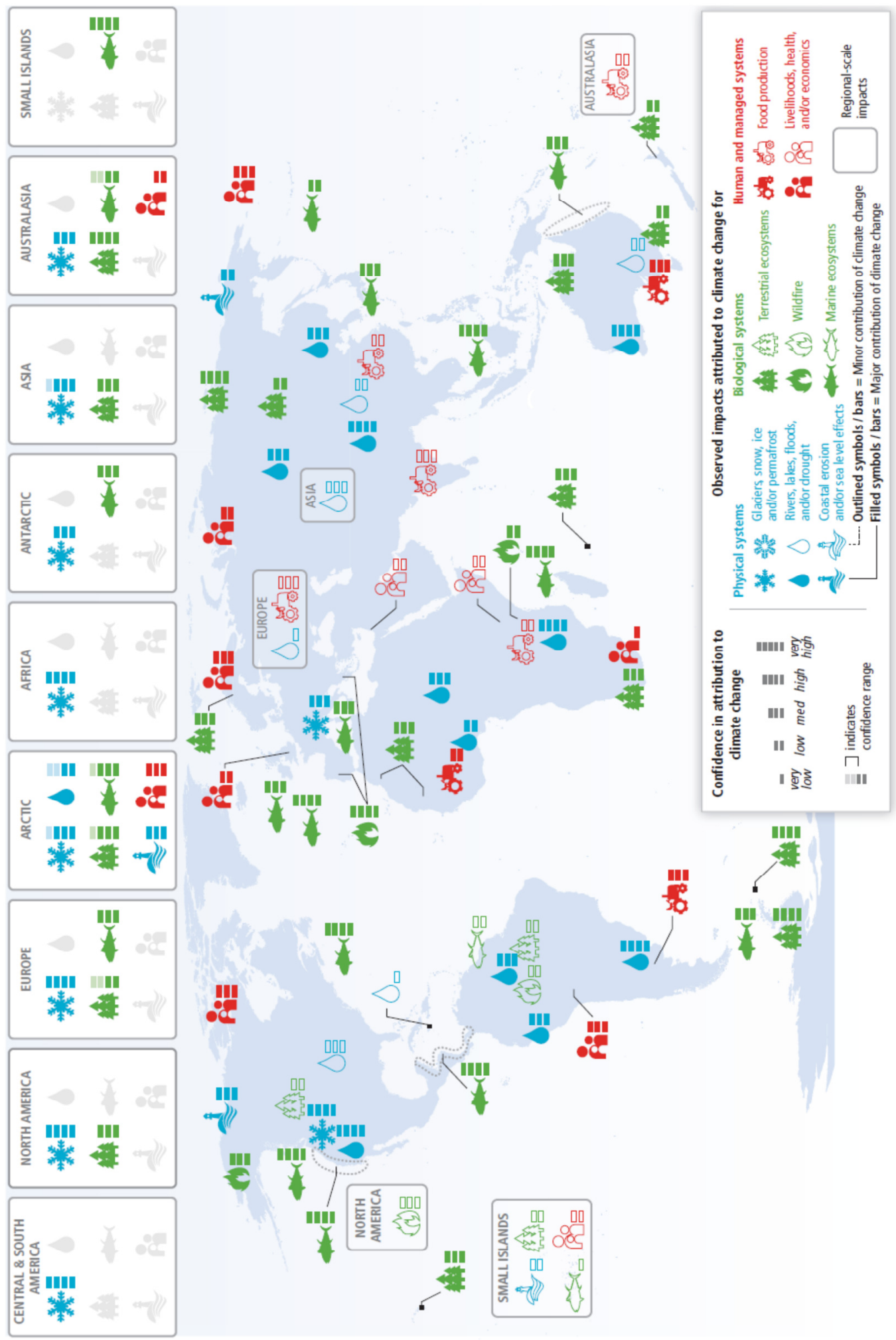


Figure 2 CRAMER, W., YOHE, G., AUfFHAMMER, M., HUGGEL, C., MOLAU, U., DIAS, M. S. \& LEEMANS, R. 2014. Detection and attribution of observed impacts. Climate Climate Change 2014: Impacts, Adaptation, and Vulnerability. Cambridge University Press : $\mathrm{p} 1011$.

Since this map could only document cases where some impacts had not only been observed but also attributed to climate change on the basis of a published scientific study, it was evident to all parties in the room that many impacts must have occurred that are not actually shown on our map. This of course was no omission; it was a clear consequence of the scientific method being applied to any part of the assessment made by the IPCC. For a number of country delegation, this appeared nevertheless as misleading, since the map apparently showed "no impacts" where in fact impacts were likely to have occurred. During some time, I tried to meet these concerns but failed to convince the delegates. The chairman of the IPCC then decided to call for a spontaneous meeting, in the corridors of the conference centre, with these delegations, myself and any other interested party. As a result of this constructive discussion in the corridor, we further strengthened the statements made in the explanatory text of the map, such as to make sure that no erroneous conclusions about the absence of observed impacts could be drawn from it. For me, this exchange was personally rewarding: it became clear to me that government delegates were very serious and wanted clear and unambiguous messages, and that the concern was that some important impacts might end up not being recognized.

A further step in the crafting of clear statements from scientific evidence, made by the IPCC, is the development of a separate Synthesis Report, aiming at drawing together the most important conclusions from the three working group reports into a shorter document. Participating, as I did, in the work of the core writing team for this report is also highly rewarding because, in an even broader setting, one has to face the challenge to debate with colleagues the relation between different findings and their importance for the policy maker (specific aspects of this process, still concerning the map from our chapter, are elaborated a commentary by Hansen \& Cramer, 2015).

In closing, I want to mention a last organizing principle for assessment work such as that of the IPCC and IPBES: throughout the various layers of summary-writing and synthesis, it is extremely important that any top level statement can be traced back to the original scientific publication and even its underlying data. In principle, this is ensured by appropriate references, and all steps of quality control need to verify that no errors or omissions occur during the editorial process. In the case of a heavy political debate that arose about the correct interpretation of some summary findings of the Fourth Assessment Report, concerning the numbers of people potentially affected by agricultural yield losses in Africa, we actually documented the "line of sight" from the summary 
statement back to the underlying scientific reference in detail (Müller $\&$ al., 2011). Doing so was useful, for two reasons. First, it demonstrated that no actual errors had been made during the assessment and subsequent synthesis. But second, it also highlighted that the underlying scientific information urgently requires a greater research effort in the future.

In the end, despite the growing availability of scientific information, it becomes undisputable that our knowledge is limited. While, in the case of changing climate and declining biodiversity, the time is well over-due to take stronger action for the preservation of the environment than what has been seen so far, it also demonstrates that for better adaptation to the inevitable, a stronger research effort is needed. Being part of this effort of research and communication has been a very enriching experience in my professional and personal life.

\section{Conclusion}

Both the 27 years of IPCC existence and the more recent IPBES experience emphasise the importance of inter-scientific dialogue and the necessity to broaden the scope beyond the core natural sciences. Although this objective is largely shared by a great majority of scientists and some significant cooperation was achieved so far, there is still room for improvement. In particular social sciences (or local and indigenous knowledge to that matter) are not there just to inform policy once the diagnosis has been produced by hard sciences, they must also be part of the definition of the problem form the onset.

The IPBES will benefit most from the IPCC experiment if it encourages the circulation of scientists between to two processes. Robert Watson's involvement in the IPBES structure is a case in point, but the participation of authors and lead authors such as the second author of this chapter are equally important. They will not only facilitate the articulation between the two series of assessments for the many overlapping issues between climate change and biodiversity loss. While IPBES certainly should avoid making the same errors as the IPCC, some "memory" from previous experiences will still be useful.

Finally, the history of building theses assessment processes through a trial and error approach shows that the debate on neutrality of "pure" science vs. politicisation of science has not been very productive. Both totally independent assessments and embedded scientific bodies can succeed or fail in making "science speak the truth to power". As social constructs, these assessment bodies will always be challenged and criticised, but such debates should not undermine the bodies' legitimacy, hence reducing their actual capacity to influence policy. This is particularly important for the IPBES future, when strong policy commitments are expected from megadiverse countries, some of which were initially sceptical about the establishment of the Platform altogether. 


\section{References}

AGRAWALA, S. 1998. "Context and early origins of the intergovernmental panel on climate change." Climatic Change, 39, 605-620.

AYKUT, S.C. \& DAHAN, A. 2011. "Le régime climatique avant et après Copenhague: sciences, politiques et l'objectif des deux degrés." Natures, Sciences et Sociétés, 19 (2), 144-157.

BECK, S., BORIE, M., CHILVERS, J. ESGUERRA, A., HEUBACH, K., HULME, M., LIDSKOG, R., LÖVBRAND, E., MARQuARD, E., MILLER, C., NADIM, T. NEßHÖVER, C., SETTELE, J., TURNHOUT, E., VASILEIAdOU, E. \& GÖRG, C. 2014. "Towards a Reflexive Turn in the Governance of Global Environmental Expertise. The Cases of the IPCC and the IPBES." GAIA- Ecological Perspectives for Science and Society, 23, 2, $80-87$.

BJURSTRÖM, A. \& POLK, M. 2011, "Physical and Economic Bias in Climate Change Research: A Scientometric Study of IPCC Third Assessment Report." Climatic Change 108, (1-2), 1-22.

BOLIN, B. 2007. A History of the Science and Politics of Climate Change: The Role of the Intergovernmental Panel on Climate Change. Cambridge (UK), Cambridge University Press.

CRAMER, W., YOHE, G., AUFFHAMMER, G., HUGGEL, C., MOLAU, U., SILVA DIAS, M.A.F., SOLOW, A., STONE, D. \& TIBIG, L. 2014. "Detection and Attribution of Observed Impacts." In FIELD, C.B., BARROS, V.R., DOKKEN, D.J., MACH, K.J., MASTRANDREA, M.D., BILIR, T.E., CHATTERJEE, M., EBI, K.L., ESTRADA, Y.O., GENOVA, R.C., GIRMA, B., KISSEL, E.S., LEVY, A.N., MAC CRACKEN, S., MASTRANDREA, P.R. \& WHITE, L.L. (eds.) Climate Change 2014: Impacts, Adaptation, and Vulnerability. Part A: Global and Sectoral Aspects. Contribution of Working Group II to the Fifth Assessment Report of the Intergovernmental Panel on Climate Change. Cambridge (UK) \& New York (NY), Cambridge University Press, 979-1037

HAAS, P.M. 1992. "Introduction: Epistemic Communities and International Policy Coordination." International Organization, "Knowledge, Power, and International Policy", 46, 1, 1-35.

HAAS, P.M. 2005. "Science and international environmental governance." In DAUVERGNE, P. ed. Handbook of Global Environmental Politics. Cheltenham UK, Edward Elgar, 383-401.

HANSEN. G., CRAMER, W. 2015. "Global distribution of observed climate change impacts." Nature Climate Change, 5, 182-185, doi: 10.1038/nclimate2529

HULME, M. \& MAHONY, M. 2010. "Climate change: What do we know about the IPCC?" Progress in Physical Geography, 34, 5, 705-718.

JASANOFF, S. 1996. "Science and Norms in Global Environmental Regimes." In HAMPSON, F.O. \& REPPY, J. (eds), Earthly Goods: Environmental Change and Social Justice, Ithaca, NY, Cornell University Press, 173-197.

IAC (InterAcademy Council). 2010. Climate change assessments: Review of the processes and procedures of the IPCC. Amsterdam: IAC. 
LARIGAUDERIE, A. \& MOONEY, H.A. 2010. "The Intergovernmental Science-Policy Platform on Biodiversity and Ecosystem Services: Moving a Step Closer to an IPCC-Like Mechanism for Biodiversity." Current Opinion in Environmental Sustainability, 2, 9-14.

LEMOS, M.C. \& MOREHOUSE, B.J. 2005. "The Co-Production of Science and Policy in Integrated Climate Assessments." Global Environmental Change, 15, 1, 57-68.

LIDSKOG, R. \& SUNDQVIST, G. 2015. "When Does Science Matter? International Relations Meets Science and Technology Studies." Global Environmental Politics, 15, 1, 1-20.

MACKENZIE, Debora (20 April 2002). "Too hot for head of climate panel". NewScientist.com. New Scientist. Consulted on 23 July 2015.

MALNES, R. 2006. "Imperfect science." Global Environmental Politics, 6, 3, 58-71.

MILLER, C.A. 2001. "Challenges in the Application of Science to Global Affairs: Contingency, Trust, and Moral Order." in MILLER, C.A. \& EDWARDS, P.N. (eds.), Changing the Atmosphere: Expert Knowledge and Environmental Governance, Cambridge (MA), MIT Press, 247-286.

MORIN, J-F. LOUAFI, S., ORSINI, A. \& OUBENAL, M. Forthcoming. "Boundary Organizations in Regime Complexes: A Social Network Assessment of IPBES."

MÜLLER, C., CRAMER, W., HARE, W.L., LOTZE-CAMPEN, H. 2011. "Climate change risks for African agriculture." PNAS, 108, 11, 4313-4315, doi : 10.1073/pnas.1015078108.

SIEBENHÜNER, B. 2003. "The changing role of nation states in international environmental assessments-the case of the IPCC." Global Environmental Change, 13, 113-123.

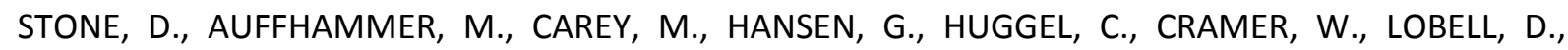
MOLAU, U., SOLOW, A., TIBIG, L., YOHE, G. 2013. "The challenge to detect and attribute effects of climate change on human and natural systems." Clim Change 121, 2, 381-395, doi: 10.1007/s10584013-0873-6.

VICTOR, D.G. 2015. "Embed the social sciences in climate policy." Nature, Comment, 520, 27-29. 